\title{
Assessment of nutritional status of the dormitory students at Nong Lam University, Ho Chi Minh City
}

\author{
Phuong T. Nguyen*, \& An T. L. Vu \\ Faculty of Food Science and Technology, Nong Lam University, Ho Chi Minh City, Vietnam
}

\begin{abstract}
ARTICLE INFO
Research Paper

Received: May 09, 2018

Revised: June 20, 2018

\section{Keywords}

BMI

Dormitory students

Malnutrition

Nutritional status

Overweight-obesity
\end{abstract}

Accepted: August 09, 2018

\section{*Corresponding author}

Nguyen Thi Phuong

Email: nguyenthiphuong@hcmuaf.edu.vn

\begin{abstract}
The objective of this study was to assess the nutritional status of the dormitory students at Nong Lam University, Ho Chi Minh City. The nutritional status was assessed based on body mass index (BMI), waist-hip ratio (WHR) and body fat percentage. Food consumption data were obtained through the application of a 24-h food recall. Socioeconomic and behavioral variables were obtained by a structured questionnaire. Results from 240 dormitory students (136 females and 104 males) showed means of BMI of $20.37 \pm 2.82 \mathrm{~kg} / \mathrm{m}^{2}$, WHR means of male and female students of 0.85 and 0.80 respectively; and the average body fat percentage was $20.13 \pm 6.49 \%$. Sixty-six percent of students were in normal health status. The proportion of students overweight-obesity was $3.75 \%$, and greater in males higher than in females. The overall malnutrition rate was $29.59 \%$, and greater in female students than in male students. Food consumption data obtained through the application of a 24-h food recall showed that dormitory students frequently consumed high-carbohydrates foods and low-fiber foods (fruits, fresh vegetables). Therefore, there is a need to implement health education interventions strategies to improve the nutritional status of students.
\end{abstract}

Cited as: Nguyen, P. T., \& Vu, A. T. L. (2019). Assessment of nutritional status of the dormitory students at Nong Lam University, Ho Chi Minh City. The Journal of Agriculture and Development 18(1), 127-135. 


\title{
Đánh giá tình trạng dinh dưỡng sinh viên nội trú Trường Đại học Nông Lâm Thành phố Hồ Chí Minh
}

\author{
Nguyễn Thị Phượng* \& Vũ Thị Lâm An \\ Khoa Công Nghệ Thực Phẩm, Trường Đại Học Nông Lâm TP. Hồ Chí Minh, TP. Hồ Chí Minh
}

\section{THÔNG TIN BÀI BÁO}

Bài báo khoa học

Ngày nhận: 09/05/2018

Ngày chỉnh sửa: 20/06/2018

Ngày chấp nhận: 09/08/2018

\section{Từ khóa}

Chỉ số khối cơ thể

Sinh viên nội trú

Suy dinh dưỡng

Thừa cân-béo phì

Tình trạng dinh dưỡng

*Tác giả liên hệ

Nguyễn Thị Phượng

Email: nguyenthiphuong@hcmuaf.edu.vn

\section{TÓM TẮT}

Mục tiêu của đề tài nhằm đánh giá tình trạng dinh dưỡng của sinh viên nội trú đang theo học (từ cuối năm nhất đến đầu năm tư) tại Đại học Nông Lâm Thành phố Hồ Chí Minh. Tình trạng dinh dưỡng được đánh giá dựa trên chỉ số khối cơ thể (BMI), tỷ lệ vòng eo-vòng mông (WHR-Waist-Hip Ratio) và tỷ lệ phần trăm mỡ cơ thể. Kết quả điều tra khẩu phần ăn được thu thập bằng phương pháp gợi nhớ 24 giờ. Việc điều tra các yếu tố kinh tế - văn hóa - xã hội được thực hiện thông qua các phiếu câu hỏi điều tra. Kết quả nghiên cứu trên 240 sinh viên nội trú (136 nữ và 104 nam) cho thấy BMI trung bình của đối tượng là $20,37 \pm 2,82 \mathrm{~kg} / \mathrm{m}^{2}$, chỉ số vòng eo trên vòng mông trung bình của nam và nữ sinh viên $(0,85 ; 0,80$; tương ứng), tỷ lệ mỡ cơ thể trung bình $(20,13 \pm 6,49)$. Kết quả thu được cho thấy $66,66 \%$ sinh viên nội trú có tình trạng sức khỏe bình thường, tỷ lệ sinh viên thừa cân - béo phì là $3,75 \%$, trong đó tỷ lệ này ở nam cao hơn so với nữ. Tỷ lệ sinh viên suy dinh dưỡng chung là $29,59 \%$, trong đó tỷ lệ này ở nữ sinh viên cao hơn nam. Kết quả thu được bằng phương pháp điều tra khẩu phần ăn - phương pháp gợi nhớ 24 giờ cho thấy sinh viên nội trú có tần suất sử dụng các thực phẩm giàu carbohydrate cao, kế đến là thịt các loại, các sản phẩm giàu chất béo và ít sử dụng các thực phẩm giàu chất xơ (trái cây, rau tươi). Như vậy, cần thiết có những biện pháp can thiệp nhằm giáo dục sức khỏe và cải thiện tình trạng dinh dưỡng của sinh viên.

\section{1. Đặt Vấn Đề}

Giai đoạn sinh viên là giai đoạn đầu tiên của thời kỳ trưởng thành sau thời kỳ trẻ em và thanh thiếu niên. Đây là giai đoạn phát triển về thể chất và trí tuệ cao, tương lai là nguồn lao động chất lượng cho quốc gia. Và đó cũng chính là khoảng thời gian mà thói quen ăn uống và lối sống có sự thay đổi rất lớn. Thực tế cho thấy rằng sinh viên lần đầu tiên xa gia đình và bắt đầu cuộc sống độc lập, thời gian dành cho việc nấu ăn bị hạn chế (Cooper \& ctv., 2009; Magda \& ctv., 2010; Hakim \& ctv., 2012). Chính chế độ ăn uống nghèo nàn, thiếu năng lượng và không cân đối các chất dinh dưỡng đã diễn ra trong suốt thời kỳ đại học cộng với việc thường xuyên bỏ bữa sáng, thích ăn các hàng quán vỉa hè, ít hoạt động thể thao, thường xuyên thức khuya...đã dẫn đến sự phát triển về thể chất và trí tuệ kém, ảnh hưởng trực tiếp đến chất lượng lao động trong tương lai của một đất nước. Hơn nữa, sinh viên đại học là một nhóm mục tiêu quan trọng đối với việc thúc đẩy lối sống lành mạnh của dân số trưởng thành (Adu \& ctv., 2009; Chourdakis \& ctv., 2010; El-Qudah \& ctv., 2012).

Trường Đại học Nông Lâm TP.HCM mỗi năm có hàng ngàn tân sinh viên nhập học, cũng như có một lượng lớn sinh viên ra trường (theo thống kê hàng năm, quy mô đào tạo hiện tại của trường là trên 23000 sinh viên với 54 ngành/chuyên ngành khác nhau), cung cấp cho xã hội một nguồn nhân lực chất lượng, đa dạng về ngành nghề. Mặc dù 
đã có một số nghiên cứu khảo sát và đánh giá tình trạng dinh dưỡng (TTDD) của sinh viên một số trường Đại học ở Việt Nam nhưng vẫn còn mang tính chất chung chung. Vì vậy, nghiên cứu "Đánh giá tình trạng dinh dưỡng của sinh viên nội trú Trường Đại học Nông Lâm TP.HCM" đã được thực hiện nhằm tìm hiểu về thực trạng tình hình dinh dưỡng của sinh viên Đại học Nông Lâm nói riêng và sinh viên các trường đại học, cao đẳng khác nói chung từ đó cung cấp những thông tin cần thiết cho những chiến lược can thiệp và dự phòng, đảm bảo và tăng cường sức khỏe cho sinh viên.

\section{Vật Liệu và Phương Pháp Nghiên Cứu}

\section{1. Đối tượng nghiên cứu}

Đối tượng nghiên cứu là sinh viên nội trú đang theo học (từ cuối năm nhất đến đầu năm tư) tại Trường Đại học Nông Lâm TP.HCM. Sinh viên cuối năm nhất được chọn khảo sát bởi vì sau một năm sống xa nhà, sinh viên đã có những thay đổi về thói quen ăn uống, lối sống nhất định, điều này phù hợp với mục tiêu nghiên cứu của đề tài. Đối với sinh viên cuối năm tư, đa số sinh viên đều đi thực tập tốt nghiệp hoặc làm thêm, sẽ rất khó để tổ chức việc điều tra.

\subsection{Thời gian và địa điểm nghiên cứu}

Nghiên cứu được thực hiện từ tháng 5/2017 đến tháng 12/2017 tại các Kí túc xá Trường Đại học Nông Lâm TP.HCM.

\subsection{Thiết kế nghiên cứu}

Sử dụng nghiên cứu cắt ngang - là một nghiên cứu dịch tễ học mô tả có phân tích qua một cuộc điều tra cắt ngang. Đây là dạng nghiên cứu mô tả giúp xác định một tỷ lệ nào đó trên dân số (Le \& ctv., 2011).

\subsection{Cỡ mẫu và cách chọn mẫu}

Cỡ mẫu dựa trên công thức ước tính cỡ mẫu cho một tỷ lệ trung bình: $n=Z_{(1-\alpha / 2)}^{2} \frac{p(1-p)}{d^{2}}$.

Trong đó: $\mathrm{n}$ là cỡ mẫu; Z là giá trị phân phố tương ứng với độ tin cậy lựa chọn (còn gọi là hệ số tin cậy, chọn độ tin cậy $95 \%$ thì giá trị $\mathrm{Z}$ là 1,96); $\mathrm{p}$ là tỷ lệ được ước tính trước trong tổng thể; $\mathrm{d}$ là sai số cho phép.
Với $\alpha=0,05 ß \mathrm{Z}_{(1-\alpha / 2)}=1,96 ; \mathrm{p}=16,7 \%$ (theo một nghiên cứu tương tự thu được tỷ lệ suy dinh dưỡng ước tính trong quần thể) ; $\mathrm{d}=$ $\pm 5 \%$. Cỡ mẫu cần thiết cho nghiên cứu là 209 sinh viên. Dự trù $15 \%$ sinh viên trong danh sách không đồng ý tham gia, như vậy tổng cộng có 240 sinh viên tham gia (Le, 2011).

\subsection{Công cự và phương pháp thu thập số liệu}

Sử dụng nhân trắc học làm phương pháp chủ yếu để đánh giá tình trạng dinh dưỡng của sinh viên (Le \& Huynh, 2011). Các thông số về chỉ số nhân trắc thu được từ việc khảo sát thực tế tại từng khu kí túc xá Trường Đại học Nông Lâm TP.HCM. Cân nặng được thu thập bằng cân điện tử Tanita BC541- Nhật Bản, có độ chính xác 0,01 kg; tỷ lệ mỡ cơ thể cũng được đo bằng cân Tanita điện tử Tanita BC541-Nhật Bản; chiều cao được đo bằng thước Stature Measure $2 \mathrm{M}$ có độ chính xác $0,1 \mathrm{~cm}$. Tình trạng dinh dưỡng của đối tượng được đánh giá theo ngưỡng phân loại của WPRO (Western Pacific Region Office), bao gồm: Suy dinh dưỡng độ III $(\mathrm{BMI}<16)$, SDD độ II $(16 \leq$ BMI $<17)$, SDD độ I $(17 \leq$ BMI $<18,5)$, bình thường $(18,5 \leq \mathrm{BMI}<23)$, thừa cân $(23 \leq \mathrm{BMI}$ $<25)$, béo phì (BMI $\geq 25$ ) (WHOEC, 2004).

Phương pháp điều tra khẩu phần ăn - hỏi ghi 24 giờ một lần được sử dụng để thu thập thông tin về loại và lượng chất dinh dưỡng có trong khẩu phần ăn hàng ngày của đối tượng; tìm hiểu thói quen ăn uống.

\subsection{Xử lý và phân tích số liệu}

Số liệu được xử lý bằng phần mềm Việt Nam Eiyokun và được phân tích bằng SPSS 16. Thống kê mô tả bao gồm trung bình, độ lệch chuẩn cho biến định lượng và tỷ lệ phần trăm cho biến định tính. Kiểm định $\mathrm{T}$ - test được sử dụng để xác định sự khác biệt về TTDD giữa các nhóm đối tượng. Hồi quy tuyến tính đa biến được áp dụng để xem xét mối liên hệ giữa TTDD và các yếu tố kinh tế - văn hóa - xã hội. Mức ý nghĩa thống kê với giá trị $\alpha=0,05$.

\section{7. Đạo đức trong nghiên cứu}

Nghiên cứu được chấp thuận bởi Ban chủ nhiệm Khoa Công Nghệ Thực Phẩm, Trường Đại học Nông Lâm TP.HCM. Các sinh viên tham gia với tinh thần tự nguyện. Thực hiện lấy số liệu vào thời điểm thuận tiện nhất: giữa giờ ra chơi, cuối 
buổi học hoặc buổi nghỉ. Nghiên cứu không ảnh hưởng đến sức khỏe, không lấy máu, không dùng thuốc điều trị. Các đối tượng tham gia được giải thích rõ về ý nghĩa và mục tiêu của cuộc điều tra. Thông tin các đối tượng cung cấp được đảm bảo giữ bí mật và chỉ phục vụ cho mục đích nghiên cứu.

\section{Kết Quả và Thảo Luận}

Nhân trắc học dinh dưỡng có mục đích đo các biến đổi về kích thước và cấu trúc cơ thể theo tuổi và tình trạng dinh dưỡng. Do đó, việc thu thập các kích thước nhân trắc là rất quan trọng trong việc nghiên cứu tình trạng dinh dưỡng của cá nhân hay cộng đồng. Thông qua các chỉ số nhân trắc ta có thể xác định được các đối tượng có tình trạng dinh dưỡng bình thường, bị suy dinh dưỡng hay bị thừa cân - béo phì. Kết quả từ Bảng 1 cho thấy cân nặng, chiều cao và BMI trung bình của nhóm đối tượng nghiên cứu là $52,31(\mathrm{~kg}), 159$ $(\mathrm{cm})$ và $20,37\left(\mathrm{~kg} / \mathrm{m}^{2}\right)$, trong đó BMI trung bình của nam cao hơn nữ. Vòng eo, vòng mông và tỷ lệ mỡ trung bình của nhóm đối tượng tương ứng là $72,89(\mathrm{~cm}), 88,71(\mathrm{~cm})$ và $20,13 \%$. Trong đó, vòng eo, vòng mông trung bình của nam sinh viên cao hơn nữ. Kết quả ở Bảng 1 cho thấy nguy cơ thừa cân - béo phì ở nam sinh viên nội trú sẽ cao hơn so với nữ sinh viên. Riêng tỷ lệ mỡ trung bình thì nữ sinh viên cao hơn, được giải thích bởi sự khác biệt về đặc điểm sinh lý cơ thể theo giới tính. Ngoài ra, có sự khác biệt về tỷ lệ mỡ cơ thể ở nam và nữ có thể còn do tác động của kích thích tố (oestrogen và progesterone ở nữ, testosterone ở nam) (Sylvia, 2010).

Nghiên cứu trên 240 sinh viên nội trú Trường Đại học Nông Lâm TP.HCM cũng cho thấy tỷ lệ sinh viên bị suy dinh dưỡng (SDD) chiếm 29,59\% (71 sinh viên), trong đó tỷ lệ ở nam là $23,07 \%$ và ở nữ là $34,56 \%$ (Bảng 2). Tỷ lệ này thấp hơn ở nghiên cứu trên sinh viên năm nhất Đại học Quốc Gia Hà Nội năm 2014 của Nguyen \& ctv. (2014) (35\%) và nghiên cứu của Phạm Văn Phú (Pham, 2011) trên sinh viên năm nhất của Trường Đại học Y Hà Nội năm 2011 là 30,9\%. Tuy nhiên kết quả này lại cao hơn so với nghiên cứu của tác giả Hoang \& ctv. (2007), khi nghiên cứu một số đặc điểm về hình thái thể lực và dinh dưỡng của 630 sinh viên Trường Đại học Y Khoa Thái Nguyên $(16 \%)$.

Bên cạnh tỷ lệ SDD, kết quả nghiên cứu ở Bảng 3 cho thấy tồn tại tình trạng TC-BP ở sinh viên nội trú Trường Đại học Nông Lâm TP.HCM, chiếm 8,75\% (21 sinh viên) tổng số đối tượng tham gia nghiên cứu, trong đó tỷ lệ ở nam là $5,76 \%$, cao gấp 2,6 lần so với ở nữ là $2,21 \%$. Tỷ lệ này cao hơn so với nghiên cứu của Nguyễn Hoàng Long là 8,3\% (Nguyen \& ctv., 2014) và Lê Bá Tường là 4,51\% (Le \& Nguyen, 2016) và thấp hơn nhiều so với tỷ lệ $\mathrm{TC}-\mathrm{BP}$ của sinh viên Trường Đại học Thăng Long trong nghiên cứu của Nguyen \& ctv. (2015) là 19,4\%.

Như vậy, kết quả ở Bảng 2, Bảng 2 và Hình 1 cho thấy trong 240 đối tượng được điều tra, có 71 sinh viên bị suy dinh dưỡng (SDD), chiếm $29,59 \%$ tổng số đối tượng nghiên cứu; và 21 sinh viên bị thừa cân - béo phì, chiếm 8,75\% tổng đối tượng nghiên cứu. Trong đó, tỷ lệ SDD ở nhóm đối tượng nghiên cứu cao hơn gấp 1,5 lần tỷ lệ TC-BP và $\mathrm{SDD}$ độ I chiếm cao nhất với tỷ lệ là $22,5 \%$. Kết quả nghiên cứu này chứng tỏ rằng ở sinh viên nội trú Trường Đại học Nông Lâm TP.HCM đang diễn ra tình trạng gánh nặng kép về dinh dưỡng. Thực vậy, cho đến nay đã có nhiều nghiên cứu về tình trạng dinh dưỡng của sinh viên Việt Nam (Tran \& Nguyen, 2005; Ho \& ctv., 2010; Ninh \& Pham, 2013) cho thấy một tỷ lệ lớn sinh viên thiếu năng lượng trường diễn và song song đó là một bộ phận không nhỏ sinh viên bị thừa cân - béo phì.

Điểm 9: tần suất 2 lần/ngày; Điểm 8: tần suất 1 lần/ngày; Điểm 7: tần suất 5 - 6 lần/tuần; Điểm 6: tần suất 3 - 4 lần/tuần; Điểm 5 : tần suất 2 lần/tuần; Điểm 4: tần suất 1 lần/tuần; Điểm 3: tần suất $2-3$ lần/tháng; Điểm 2 : tần suất 1 lần/tháng; Điểm 1 : tần suất dưới 1 lần/tháng.

Kết quả điều tra từ Bảng 4 cho thấy gạo là loại lương thực được tiêu thụ nhiều nhất và với tần suất thường xuyên nhất, khoảng 2 lần/ngày. Tiếp đến là trứng gà/vịt với tần suất 2 lần/tuần, các thực phẩm nhiều dầu mỡ, thịt các loại và sữa với tần suất $2-3$ lần/tuần. Việc tiêu thụ thịt các loại, trứng gà/vịt ở sinh viên nội trú nhiều hơn so với việc tiêu thụ cá và hải sản các loại, có thể do trứng là thực phẩm ngon, bổ, rẻ, dễ chế biến, nhất là sinh viên có thói quen ăn mì trứng hoặc bánh mì ốp la hoặc cũng có thể là do đặc điểm các hàng quán ăn xung quanh ký túc xá của trường thường cung cấp các món ăn chủ yếu từ thịt, trứng như: thịt kho tiêu, sườn ram, sườn xào chua ngọt, đùi gà chiên, thịt kho trứng, chả trứng, đậu hủ nhồi thịt,...

Bên cạnh đó thì trái cây cũng được sử dụng với tần suất 1 - 2 lần/tuần. Tuy nhiên theo kết quả 
Bảng 1. Đặc điểm nhân trắc của sinh viên nội trú Trường Đại học Nông Lâm TP.HCM

\begin{tabular}{lccc}
\hline \multirow{2}{*}{ Chỉ số nhân trắc } & \multirow{2}{*}{ Mẫu nghiên cứu } & \multicolumn{2}{c}{ Giới tính } \\
\cline { 3 - 4 } & & Nam & Nữ \\
\hline Cân nặng trung bình $(\mathrm{kg})$ & $52,31 \pm 10,31$ & $59,45 \pm 10,84$ & $46,84 \pm 5,39$ \\
Chiều cao trung bình $(\mathrm{cm})$ & $159 \pm 0,07$ & $165 \pm 0,07$ & $156 \pm 0,05$ \\
BMI & $20,37 \pm 2,82$ & $21,86 \pm 3,24$ & $19,22 \pm 1,73$ \\
Vòng eo trung bình $(\mathrm{cm})$ & $72,89 \pm 6,89$ & $75,71 \pm 7,12$ & $70,74 \pm 5,89$ \\
Vòng mông trung bình $(\mathrm{cm})$ & $88,71 \pm 5,61$ & $89,39 \pm 6,16$ & $88,20 \pm 4,64$ \\
WHR & $0,82 \pm 0,06$ & $0,85 \pm 0,05$ & $0,80 \pm 0,05$ \\
Tỷ lệ mỡ trung bình $(\mathrm{cm})$ & $20,13 \pm 6,49$ & $15,37 \pm 5,78$ & $23,8 \pm 4,22$ \\
\hline
\end{tabular}

Bảng 2. Tình trạng suy dinh dưỡng ở sinh viên nội trú Trường Đại học Nông Lâm TP.HCM

\begin{tabular}{|c|c|c|c|c|c|c|c|c|}
\hline \multirow{2}{*}{ TTDD } & \multirow{2}{*}{ BMI $\left(\mathrm{kg} / \mathrm{m}^{2}\right)$} & \multicolumn{2}{|c|}{ Nam } & \multicolumn{2}{|c|}{ Nữ } & \multicolumn{2}{|c|}{ Chung } & \multirow[b]{2}{*}{$P$} \\
\hline & & $\mathrm{X}^{*}$ & $\% * *$ & $\mathrm{X}^{*}$ & $\%^{* *}$ & $\mathrm{X}^{*}$ & $\%^{* *}$ & \\
\hline SDD & $<18,5$ & 24 & 23,07 & 47 & $\overline{34,56}$ & 71 & 29,59 & \\
\hline SDD độ I & $17-18,49$ & 19 & 18,27 & 35 & 25,74 & 54 & 22,5 & \\
\hline SDD độ 2 & $16-16,9$ & 4 & 3,84 & 9 & 6,62 & 13 & 5,42 & $<0,05$ \\
\hline SDD độ 3 & $\leq 16$ & 1 & 0,96 & 3 & 2,2 & 4 & 1,63 & \\
\hline
\end{tabular}

* Số lượng, ** Tỷ lệ phần trăm.

Bảng 3. Tình trạng $\mathrm{TC}$ - $\mathrm{BP}$ (thừa cân-béo phì) ở sinh viên nội trú Trường Đại học Nông Lâm TP.HCM

\begin{tabular}{|c|c|c|c|c|c|c|c|c|}
\hline \multirow{2}{*}{ TTDD } & \multirow{2}{*}{ BMI $\left(\mathrm{kg} / \mathrm{m}^{2}\right)$} & \multicolumn{2}{|c|}{ Nam } & \multicolumn{2}{|c|}{ Nữ } & \multicolumn{2}{|c|}{ Chung } & \multirow{2}{*}{$P$} \\
\hline & & $\mathrm{X}^{*}$ & $\% * *$ & $\mathrm{X}^{*}$ & $\% * *$ & $\mathrm{X}^{*}$ & $\%^{* *}$ & \\
\hline$\overline{\mathrm{TC}}-\mathrm{BP}$ & $\geq 23$ & 12 & 5,76 & 6 & 2,21 & 21 & 8,75 & \\
\hline Béo phì & $\geq 25$ & 4 & 1,92 & 2 & 0,74 & 6 & 1,25 & $<0,05$ \\
\hline Thừa cân & $23-24,9$ & 8 & 3,84 & 4 & 1,47 & 12 & 2,5 & \\
\hline
\end{tabular}

* Số lượng, ** Tỷ lệ phần trăm.

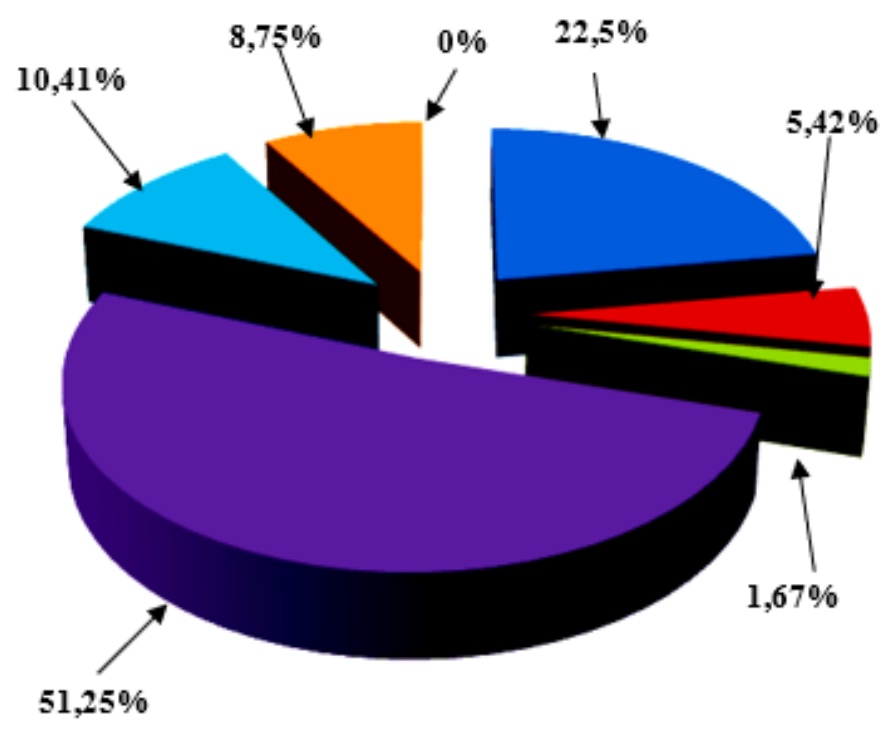

Suy dinh dưỡng Độ I $(\mathrm{n}=54)$

- Suy dinh dưỡng Độ II $(n=13)$

- Suy dinh dưỡng Độ III $(n=4)$

- Bình thường $(\mathrm{n}=123)$

- Thừa cân $(\mathrm{n}=25)$

Béo phì độ $\mathrm{I}(\mathrm{n}=21)$

Béo phì độ II $(n=0)$

Hình 1. Tình trạng dinh dưỡng của sinh viên nội trú Trường Đại học Nông Lâm TP.HCM. 
Bảng 4. Mức tiêu thụ lương thực thực phẩm qua 24 giờ của sinh viên nội trú Trường Đại học Nông Lâm TP.HCM

\begin{tabular}{lc}
\hline Nhóm thực phẩm & Tần suất* \\
\hline Gạo & $8,52 \pm 0,89$ \\
Lương thực khác (ngô, khoai,...) & $2,71 \pm 0,96$ \\
Thịt các loại & $3,32 \pm 1,10$ \\
Tôm, cá, hải sản khác & $1,30 \pm 0,83$ \\
Trứng gà, vịt & $5,03 \pm 1,68$ \\
Dầu, mỡ, hạt có dầu & $3,74 \pm 1,68$ \\
Sữa & $3,16 \pm 1,35$ \\
Trái cây (chủ yếu là cốc, xoài và ổi) & $4,64 \pm 1,78$ \\
\hline
\end{tabular}

* Tần suất sử dụng thực phẩm được đánh giá theo thang điểm 9.

điều tra thì nhóm đối tượng được nghiên cứu chủ yếu tiêu thụ các loại trái cây có vị chua như cóc, ổi, xoài, điều này cho thấy việc tiêu thụ trái cây ở sinh viên nội trú Đại học Nông Lâm TPHCM không được đa dạng. Tóm lại, loại thực phẩm mà nhóm sinh viên nội trú ưu tiên sử dụng là thực phẩm giàu carbohydrate, kế đến là các loại thịt, thủy hải sản, trứng và các thực phẩm giàu chất béo. Năm 2012, El-Qudah \& ctv. đã nghiên cứu về tình trạng dinh dưỡng và tập quán ăn uống của sinh viên một trường đại học ở tây bắc Vương Quốc Ả Rập cho thấy tỷ lệ thừa cân là $22,6 \%$, tỷ lệ béo phì chiếm $11,6 \%$ và thiếu cân chiếm $13,7 \%$, trong đó tỷ lệ nam bị thừa cân béo phì cao hơn nữ giới. Đồng thời, có khoảng $15,7 \%$ sinh viên thường xuyên bỏ bữa sáng, hơn $58 \%$ sinh viên cho biết rằng họ thường xuyên ăn thức ăn nhanh. Sinh viên nam thích ăn bánh mì kẹp thịt, khoai tây chiên và các loại thịt đỏ, trong khi nữ sinh lại thích ăn bánh kẹo và sô cô la.

Kết quả giá trị dinh dưỡng trong khẩu phần ăn của sinh viên được tính bằng phần mềm Việt Nam Eiyokun ở Bảng 5 cho thấy năng lượng trung bình từ khẩu phần của sinh viên nội trú là 1732 \pm 181,4 Kcal/người/ngày, đạt mức độ đáp ứng so với NCKN là $87,47 \%$. Trong đó lipid tổng số có mức độ đáp ứng cao nhất trong 3 nhóm chất dinh dưỡng sinh năng lượng $(95,64 \%)$, carbohydrate chiếm 63,5\% năng lượng khẩu phần, đáp ứng 85,47\% nhu cầu năng lượng khẩu phần ăn của đối tượng và protein cung cấp khoảng 16,3\% đạt 90,58\% năng lượng khẩu phần ăn. Riêng với các vi chất dinh dưỡng, mức độ đáp ứng khá cao nhất là chất kẽm có mức độ đáp ứng cao nhất trong các chất dinh dưỡng đa lượng, đạt tới $97,78 \%$ nhu cầu khuyến nghị. Tiếp theo sau là calci và chất sắt, với mức độ đáp ứng lần lượt là 78,94\% và $73,04 \%$. Riêng Iod có mức độ đáp ứng còn quá thấp so với nhu cầu khuyến nghị, chỉ đạt 4,93\%. Về mức độ đáp ứng nhu cầu khuyến nghị của nhóm vitamin, vitamin $\mathrm{C}$ và vitamin $\mathrm{B}$ vượt mức khuyến nghị (115,5\% và $125 \%)$ trong khi vitamin $\mathrm{A}$ có mức độ đáp ứng chỉ đạt 26,05\% nhu cầu khuyến nghị. Kết quả Bảng 6 cho thấy nhóm sinh viên TC BP có thói quen ăn vặt cao hơn với nhóm sinh viên SDD, khác biệt có ý nghĩa thống kê với $P<$ 0,001 . Tỷ lệ sinh viên thích ăn khuya ở nhóm TC - BP là $36,25 \%$, cao hơn nhóm SDD là 16,25\%, sự khác biệt với $P<0,001$. Tỷ lệ thích ăn bánh kẹo ngọt, các món chiên/rán ở nhóm sinh viên TC - BP cũng cao hơn so với nhóm sinh viên SDD, khác biệt có ý nghĩa với $P<0,05$. Bên cạnh đó, tỷ lệ sử dụng thực phẩm giàu lipid, protein ở nhóm sinh viên $\mathrm{SDD}$ và nhóm $\mathrm{TC}-\mathrm{BP}$ không có sự khác biệt về mặt thống kê, với $P>0,05$. Từ kết quả này, cho thấy được rằng nhóm đối tượng $\mathrm{TC}$ - BP có xu hướng thích ăn những loại thực phẩm cung cấp nhiều năng lượng trong chế độ ăn của mình hơn là nhóm đối tượng bị suy dinh dưỡng.

Năm 2010, Magda \& ctv. đã nghiên cứu về tình trạng dinh dưỡng và thói quen ăn uống của sinh viên các trường đại học, cao đẳng ở Đông Bohemia, kết quả cho thấy tỷ lệ thừa cân - béo phì là $43 \%$ (nam chiếm tỷ lệ cao hơn nữ), tỷ lệ thiếu cân chiếm $9 \%$ (chủ yếu là nữ). Có hơn $90 \%$ sinh viên trả lời rằng họ có thói quen ăn nhanh, ăn vội và ăn nhiều, hơn $30 \%$ thường loại bỏ bớt thức ăn trong khẩu phần của mình vì nhiều lí do, có thể là do dị ứng với thức ăn, khoảng $50 \%$ sinh viên thường xuyên ăn trưa tại căn tin của trường. Nghiên cứu cũng nhấn mạnh rằng chế độ dinh dưỡng và luyện tập thể thao có vai trò rất quan trọng đối với sức khỏe của sinh viên. Đồng thời, việc thường xuyên giáo dục, nâng cao nhận thức của sinh viên về một chế độ dinh dưỡng hợp lý là hết sức cần thiết. Năm 2015, Lupi \& ctv. đã 
Bảng 5. Giá trị dinh dưỡng khẩu phần của sinh viên nội trú Trường Đại học Nông Lâm TP.HCM và mức đáp ứng nhu cầu khuyến nghị 2016

\begin{tabular}{lccc}
\hline Chất dinh dưỡng & Trung bình $\pm \mathrm{SD}$ & $\begin{array}{c}\text { Nhu cầu khuyến nghị } \\
(\mathrm{NCKN}) 2016\end{array}$ & $\begin{array}{c}\text { Mức độ đáp ứng } \\
(\%)\end{array}$ \\
\hline Năng lượng (Kcal) & $1732 \pm 181,4$ & 1980 & 87,47 \\
Carbohydrate (g) & $275,3 \pm 86,4$ & $55-65 \%$ & 85,47 \\
Lipid (g) & $52,6 \pm 22,9$ & $20-25 \%$ & 95,64 \\
Protein (g) & $70,6 \pm 20,8$ & $13-20 \%$ & 90,58 \\
Calci $(\mathrm{mg})$ & $631,53 \pm 55,2$ & 800 & 78,94 \\
Sắt $(\mathrm{mg})$ & $16,8 \pm 19,8$ & 23 & 73,04 \\
Kẽm $(\mathrm{mg})$ & $8,8 \pm 1,7$ & 9 & 97,78 \\
Iod $(\mu \mathrm{g})$ & $7,4 \pm 5,2$ & 150 & 4,93 \\
Vit A (mg) & $195,4 \pm 156,6$ & 750 & 26,05 \\
Vit C (mg) & $115,5 \pm 30,9$ & 100 & 115,50 \\
Vit B1 (mg) & $1,5 \pm 0,8$ & 1,2 & 125,00 \\
Vit B2 $(\mathrm{mg})$ & $1,3 \pm 0,7$ & 1,35 & 96,30 \\
\hline
\end{tabular}

Bảng 6. Mối liên quan giữa thói quen ăn uống và tình trạng dinh dưỡng sinh viên nội trú Trường Đại học Nông Lâm TP.HCM

\begin{tabular}{|c|c|c|c|c|c|c|c|}
\hline \multirow[t]{2}{*}{ Thói quen ăn uống } & \multicolumn{2}{|c|}{$\begin{array}{c}\text { SDD } \\
\mathrm{n}=71\end{array}$} & \multicolumn{2}{|c|}{$\begin{array}{c}\text { Bình thường } \\
\mathrm{n}=123\end{array}$} & \multicolumn{2}{|c|}{$\begin{array}{l}\text { TC-BP } \\
\mathrm{n}=46\end{array}$} & \multirow{2}{*}{$P$} \\
\hline & $\mathrm{SL}^{*}$ & $\%$ & SL & $\%$ & SL & $\%$ & \\
\hline \multicolumn{8}{|l|}{ Ăn vặt } \\
\hline Thường xuyên (TX) & 17 & 17,71 & 46 & 47,92 & 33 & 34,38 & $<0,001$ \\
\hline Không TX & 54 & 32,84 & 77 & 57,46 & 13 & 9,7 & \\
\hline \multicolumn{8}{|l|}{ Ăn khuya } \\
\hline Thường xuyên & 13 & 16,25 & 38 & 47,5 & 29 & 36,25 & $<0,001$ \\
\hline Không TX & 58 & 37,18 & 81 & 51,92 & 17 & 10,9 & \\
\hline \multicolumn{8}{|l|}{ Thích bánh kẹo ngọt } \\
\hline Thường xuyên & 22 & 20,95 & 41 & 39,05 & 42 & 40 & $<0,01$ \\
\hline Không TX & 49 & 36,3 & 82 & 60,74 & 4 & 2,96 & \\
\hline \multicolumn{8}{|l|}{ Thực phẩm giàu Carb } \\
\hline Thường xuyên 45 & 29,03 & 73 & 47,1 & 37 & 23,87 & & $<0,05$ \\
\hline Không TX & 26 & 27,37 & 60 & 63,16 & 9 & 9,47 & \\
\hline \multicolumn{8}{|l|}{ Thực phẩm giàu Protein } \\
\hline Thường xuyên & 23 & 17,56 & 81 & 61,83 & 27 & 20,61 & $>0,05$ \\
\hline Không TX & 48 & 44,04 & 42 & 38,53 & 19 & 17,43 & \\
\hline \multicolumn{8}{|l|}{ Thực phẩm giàu Lipid } \\
\hline Thường xuyên & 32 & 26,24 & 59 & 48,36 & 31 & 25,4 & $>0,05$ \\
\hline Không TX & 39 & 33,05 & 64 & 54,24 & 15 & 12,71 & \\
\hline \multicolumn{8}{|l|}{ Thích món chiên/rán } \\
\hline Thường xuyên & 21 & 21,85 & 47 & 48,96 & 28 & 29,19 & $<0,05$ \\
\hline Không TX & 50 & 34,72 & 76 & 52,78 & 18 & 12,5 & \\
\hline
\end{tabular}

*SL: Số lượng.

tiến hành đánh giá thói quen ăn uống và lối sống của sinh viên trường đại học Ferrara, Bắc Ý. Kết quả nghiên cứu cho thấy sinh viên sống xa gia đình ít luyện tập thể thao hơn và ít tiêu thụ rau củ được nấu chín, ít tiêu thụ trái cây tươi, không thường xuyên tiêu thụ các loại ngũ cốc, bánh mì, trứng so với sinh viên sống ở nhà cùng bố mẹ. Trong khi đó, sinh viên đại học sống xa nhà lại thường xuyên tiêu thụ thức ăn nhanh, thực phẩm đóng gói sẵn, khoai tây chiên. Phần lớn sinh viên 
cho biết rằng lối sống và thói quen ăn uống của họ đã thay đổi rất nhiều kể từ khi rời xa gia đình. Và phần đông sinh viên đại học mong muốn có sự can thiệp giáo dục dinh dưỡng vào đại học bởi vì hiện tại, các biện pháp cải thiện tình trạng dinh dưỡng và lối sống cho sinh viên đại học dường như bị bỏ quên.

\section{Kết Luận}

Kết quả thu được là $66,7 \%$ sinh viên nội trú có tình trạng sức khỏe bình thường, tỷ lệ sinh viên bị thừa cân - béo phì là $3,75 \%$, trong đó tỷ lệ ở nam cao hơn so với nữ. Tỷ lệ sinh viên bị suy dinh dưỡng là 29,59\%, trong đó nam sinh viên ít hơn so với nữ sinh viên. Sinh viên nội trú Trường Đại học Nông Lâm TP.HCM có tần suất tiêu thụ thực phẩm giàu carbohydrate cao và hạn chế ở nhóm thực phẩm bảo vệ (rau, củ, quả tươi). Riêng nhóm đối tượng thừa cân — béo phì có thói quen thường xuyên ăn tỉ thực phẩm giàu chất béo và các món ăn chiên, rán. Từ các kết quả thu được của đề tài, cần thiết có những biện pháp can thiệp nhằm giáo dục sức khỏe và cải thiện tình trạng dinh dưỡng của sinh viên, chẳng hạn, Nhà trường chỉ đạo và tạo điều kiện để Đoàn thanh niên, Hội sinh viên lấy sinh viên Bộ môn Dinh Dưỡng Người - Khoa Công Nghệ Thực Phẩm làm nòng cốt, tăng cường truyền thông giáo dục sức khỏe cho sinh viên toàn trường, trong đó nhấn mạnh nội dung về hậu quả của tình trạng suy dinh dưỡng và tác hại của thừa cân - béo phì đối với sức khỏe.

\section{Lời Cảm Ơn}

Xin chân thành cảm ơn Trường Đại học Nông Lâm TP.HCM đã tài trợ cho chúng tôi thực hiện đề tài này.

\section{Tài Liệu Tham Khảo (References)}

Adu, O. B., Falade, A. M., Nwalutu, E. J., Elemo, B. O., \& Magbagbeola, O. A. (2009). Nutritional status of undergraduates in a Negerian university in south west Nigeria. International Journal of Medicine and Medical Sciences 1(8), 318-324.

Chourdakis, M., Tzellos, T., Papazisis, G., Toulis, K., \& Kouvelas, D. (2010). Eating habits, health attitudes and obesity indices among medical students in northern Greece. Appetite 55(3), 722-725.

Cooper, R. G., \& Chifamba, J. (2009). The nutrition intake of undergradutes at the University of Zimbabwe
College of Health Sciences. Tanzania Journal of Health Research 11(1), 35-39.

El-Qudah, J. M., Al-Omran, H., Abu-Alsoud, B., \& AlShek Yousef, T. O. I. (2012). Nutritional status among a sample of Saudi college students. Curent Research Journal of Biological Sciences 4(5), 557-562.

Hakim, N. H. A., Muniandy, N. D., \& Ajau, D. (2012). Nutritionlal status and practices among university students in selected universities in Selangor, Malaysia. Asian Journal of Clinical Nutrition 4(3), 77-87.

Hoang S. T., Nguyen, T. X., \& Trinh, D. X. (2007). Physical and nutrient characteristics of students at Thai Nguyen Medical College. Vietnam Journal of Physiology 11(1), 42-46.

Ho, M. T., Pham, H. V., \& Nguyen, B. H. (2010). Nutritional status, dietary and other factors relating to nutrition of 6 to 14-year students at Soc Son, Ha Noi. Journal of Food and Nutrition Science 6(2), 23-31.

Le, H. T., \& Huynh, P. N. (2011). Unification of nutritional stutus evaluation using anthropometry. Journal of Food and Nutrition Science 7(2), 1-7.

Le, N. H. (2011). Sampling method and sample size determination in medical research. Ha Noi, Vietnam: Medical Publishing House.

Le, T. B., \& Nguyen, T. H. (2016). The obese situation survey of student in Can Tho University. Can Tho University Journal of Science 44, 9-13.

Lupi, S., Bagordo, F., Stefanati, A., Grassi, T., Piccnni, L., Bergamini, M., \& Donno A. D. (2015). Assessment of lifestyle and eating habits among undergraduate students in northern Italy. American Journal of Food, Agriculture, Nutrition and Development 51(2), 154-161.

Magda, T., Magdalena, R., \& Gabriela, S. (2010). Nutrition status dietary habits of high school and college students. Health Education: International Exiperiences 21, 389-397.

Nguyen, B. N., Duong, A. H., \& Le, H. T. (2015). The overweight and obesity scenarios of new students at Thang Long University from 2012-2014 and factors related to these scenarios. Research proceeding (Part II: 167-175). Ha Noi, Vietnam: Thang Long University.

Nguyen, L. H., Hoang, T. M., Nguyen, T. T., Nguyen, S. T., \& Dang, N. D. (2014). Quality of life and nutrition status among first - year students of Vietnam national university, Ha Noi. Vietnam Journal of Preventive Medicine 24(6), 96-102.

Ninh, N. T., \& Pham, H. T. (2013). Nutritional status of full-time students in university and college at Nam Dinh Province in 2012. Journal of Practical Medicine 5, 93-96.

Pham, P. V. (2011). Nutrition status among first - year students and factors affect the status at Ha Noi Medical University. Journal of Medical Research 74(3), 344349. 
Sylvia, K. (2010). Gender differences in body composition from childhood to old age: an evolutionary point of view. Journal of Life Science 2(1), 1-10.

Tran, L. T. H., \& Nguyen, H. T. K. (2005). The overweight and obesity scenarios of population groups at Ho Chi Minh City from 1996 to 2001. Journal of Food and Nutrition Science 1(1), 74-80.
WHOEC (World Health Organization Expert Consultation). (2004). Appropriate body mass index for Asian populations and its implications for policy and intervention strategies. Lancet 363(9403), 157-163. 